\title{
Keynes on Expectations, Uncertainty and Defensive Behavior
}

\author{
Fernando J. Cardim de Carvalho*
}

\begin{abstract}
Keynesianism dominated macroeconomics until the early 1970s in the form of what was called hydraulic Keynesianism, a fundamentally mechanistic approach that assumed that economic agents always reacted in the same way to a certain set of stimuli. The dominance of hydraulic Keynesianism opened the way for the emerging criticism, first by Milton Friedman, and later by New Classical economists, that Keynesianism had no place for expectations. Keynes, however, dedicated close attention to the ways expectations were formed under fundamental uncertainty and how economic behavior was changed when agents acknowledged that the future was uncertain. For Keynes, acknowledging uncertainty meant that agents sought to take precautions against the possibility that their expectations were wrong and the decisions relying on them were incorrect. In The General Theory, Keynes showed that, in practically all fields, behavior would be significantly changed when agents acknowledged uncertainty. Precautionary savings, liquidity preference, conventional behavior, were all particular manifestations of the attempt to get protection against the losses that could result from the disappointment of expectations.
\end{abstract}

Keywords: Expectations; Uncertainty; Defensive Behavior

JEL Classification: A 12; B 22; E 12; E 41

* Fernando J. Cardim de Carvalho is Professor of Institute of Economics, Federal University of Rio de Janeiro (Brazil) and Patron of the Brazilian Keynesian Association. 


\section{Introduction}

Between the end of World War Two and the mid-1960's, a Keynesian consensus dominated both macroeconomic theory and policy-making, most strongly in the Anglo-Saxon countries, but in one way or another also practically everywhere in the (then) non-communist world. Keynesian macroeconomics consisted, in fact, of a set of propositions that were collectively known as the Neoclassical Synthesis, a label Paul Samuelson attached to it in his Economics, for decades the most influential Economics textbook of the Twentieth Century. Its main pillar was the aggregate demand and supply analysis formalized by Samuelson himself (the 45-degree cross) and, even more importantly, by John Hicks (the IS/LM model). Keynesian policy doctrine could be summarized in two propositions: 1. Modern market economies cannot spontaneously guarantee full utilization of their productive resources, including labor, in the short run because actual aggregate demand could be lower than potential output; 2 . The government could, using monetary and/or fiscal policies ${ }^{1}$, make up for any short-term deficiency in private demand; it could thus manage aggregate demand so as to achieve the level of unemployment where all workers willing to work at the going wage could find a job, avoiding at the same time any excess demand pressure that could lead to price inflation. In the heyday of Keynesianism, that is, in the early 1960's, the expression fine tuning was introduced to describe aggregate demand management policies intended to maintain the economy operating at full employment. ${ }^{2}$

The firm belief in the efficacy of demand management policies to fine tune the economy (achieving the combination between unemployment and inflation rates society desired at each moment) was strengthened by another result of Keynesian dominance among macroeconomic theorists, the widespread drive to build large-scale macroeconometric models. These models were expected not only to describe accurately the operating mechanisms of a given economy but also serve as the main source of information for the design of policy instruments to governments.

Triumphant Keynesianism was a Cartesian monument to mechanistic views of the economy which was approached as if it worked like a machine. Pushing the right buttons, pulling the right levers, it should be possible to a technically prepared government to adjust aggregate demand to fullemployment output without generating unwanted inflationary pressures.

Critics used to label this strand of Keynesian economics hydraulic Keynesianism, emphasizing its mechanistic nature. The criticism was not really far off the mark in relation to Samuelson's Neoclassical synthesis, to the macroeconometric models derived from it and even to some less orthodox versions of effective demand theory which emphasized the stability of the structural functions that defined the operation of the economy. In the 1960's, however, developed economies were operating in an increasingly disordered way. In this context, hydraulic Keynesianism was to become an easy target for criticisms based on the notion that human behavior, even when it obeys laws and rules, is more flexible than it had been assumed. First Milton Friedman, and later Robert Lucas, among others, argued that Keynesian macroeconomics neglected the possibility that agents would learn from their experience, including in dealing with government intervention, and that as a result they could react differently to

\footnotetext{
${ }^{1}$ In fact, strong faith was invested in the efficacy of fiscal policy, not so much trust surrounded monetary policies, largely assumed to be cursed by what was then called "pessimism of elasticities". It was generally believed that the money demand function was highly interest-elastic while the investment expenditure function (believed to be the main transmission channel between monetary policy and real activity) was highly interest-inelastic. Under these conditions, monetary policy could only be a poor instrument to properly manage aggregate demand behavior.

${ }^{2}$ Perhaps the most important work of the period documenting the view that governments could adjust aggregate demand so finely was Heller (1966). Walter Heller was the chairman of the Council of Economic Advisors to President Lyndon Johnson. A social reformer and a firm believer in the efficacy of Keynesian policies he wrote the 1966 book almost as a manifesto in favor of enlightened employment policies by governments.
} 
the same stimulus at different dates. People's views mattered and their expectations should be taken into consideration in the formulation of any macroeconomic theory. The theoretical criticism inaugurated by Friedman with his adaptive expectation hypothesis, was to be followed by a criticism of structural macroeconometric models by Lucas, in the development of the rational expectations hypothesis.

We are not particularly interested in the reasons why Keynesianism evolved into its hydraulic version or whether Friedman's and Lucas' criticisms were appropriate or even if their alternative hypotheses really represented any progress from a theoretical point of view. In this paper, we assume an alternative starting point, represented not by the Neoclassical Synthesis, but (freely paraphrasing Axel Leijonhufvud) by the Economics of Keynes.

The criticism directed at the mechanistic nature of Keynesian theory is singularly inappropriate when applied to Keynes himself (and the authors that claimed his legacy on these matters). Expectations and behavior under uncertainty were in fact lifelong interests of Keynes's. One of his first major works, written before he had even decided to become an economist, was called Treatise on Probability, and was an investigation of the possibility of acting rationally under uncertainty. These ideas and concerns were to accompany Keynes for all his intellectual life and to become a central element of the theory he came to propose in his opus magnum, The General Theory of Employment, Interest and Money (Keynes, 2007).

It is argued in this paper that the most important theoretical innovations advanced by Keynes in The General Theory are in fact developments or applications of his views on behavior under uncertainty. We begin, in section two, by offering a quick summary of Keynes's approach to expectations and decision-making, from the Treatise on Probability to The General Theory, drawing a few general implications of the theory that is proposed. In section III we show that all three pillars of effective demand theory, the propensity to consume, the marginal efficiency of capital and liquidity preference, rely on the same fundamental pattern of behavior described in the preceding section. Section IV introduces Minsky's model of financial fragility as a development of the same basic assumptions proposed by Keynes to illustrate how flexible those assumptions are in terms of theoretical predictions. Section $\mathrm{V}$ concludes.

\section{From the Treatise on Probability to The General Theory}

Keynes's first major contribution to the study of behavior under uncertainty and the formation of expectations was his Treatise on Probability, originally published in 1921, but written about ten years earlier. Keynes had not yet decided to become an economist when the work was prepared but his concern was to investigate the possibility of rational behavior under uncertainty, that is, when decision is based on probabilities rather than on certainties.

Keynes followed the logic probability school, not the frequentist approach. The aim of the logic probability school was not to count cases to measure the frequency of events. In fact, logic probability is more frequently non-numerical than the opposite. The goal is to study probability as a foundation for induction, again not as a branch of epistemology but as a basis for rational behavior. If knowledge obtained by induction, i.e. by direct observation, is by its own nature incomplete, how can one make rational decisions on the basis of incomplete information? The study of probability was the study of decision making when the relevant information to achieve certainty is partly unavailable. If one cannot anticipate a given effect as implied with certainty by a definite cause on the basis of available information, one has to decide which events among a set of possibilities are probable, or, in other words, what should the decision-maker believe to be the more likely effects resulting of a given cause 
(such as a decision made by the individual). As Keynes put it, "[p]robability is the study of the grounds which lead us to entertain a rational preference for one belief over another." (Keynes, 1973a, p. 106)

Here is not the place to present Keynes's full approach to probability and decision making. ${ }^{3}$ For our purposes in this paper it suffices to say that according to the Treatise, one can obtain knowledge both by observation (or direct knowledge, as he wrote) and by argument. Leaving aside the debate around whether observations can be really relied upon to generate true knowledge, a philosophical point Keynes does not seem particularly interested in, probability has to do with knowledge obtained by argument, which Keynes meant as being obtained as implication of the premises taken as direct knowledge. According to Keynes, deriving implications of premises is a logical process, objective in nature in the sense that logic rules are the same no matter which individual is applying them. But if premises are true and the derivation of implications has to be logical, why would one be concerned with probabilities? Keynes's point is that direct knowledge, even if true, is seldom complete. Observable premises have to be completed with conjectures to enable the decision-maker to derive their logical implications. In other words, one does not start from true knowledge alone but has to complement it with conjectural premises. If more than one set of conjectures is possible, implied results are conditioned by the set of conjectures selected by the decision maker and are, therefore, probabilistic. The choice of conjectures is subjective. The knowledge by the decision-maker that at least part of his or her premises was obtained by conjecture rather than direct observation raises the inter-related problems of belief and of confidence in beliefs.

Thus, in the Treatise Keynes was already concerned with rational decision-making on the basis of incomplete hard information and the roles of conjectures and of confidence. When Keynes chose to dedicate his time to the study of economics he brought this approach to his new field. It is important to note that Keynes's concern was with rational behavior and the nature of the information on which decision making is based. In his works, he never turned to the possibility that expectations (and the behavior patterns they led to) were irrational. In fact, Keynes rejected the hypothesis that agents behaved irrationally both on theoretical and on empirical grounds. As Shackle (1979) would put it, Keynesian agents make their choices as rationally as neoclassical agents. The difference is that, under uncertainty, agents choose among a subjectively-created list of outcomes while orthodox analysis postulates choice among objectively-determined lists of outcomes. ${ }^{4,5}$

As a result, and contrary to what is postulated by, say, the rational expectations hypothesis, the same informational set can lead to different expected outcomes (depending on which conjectures are used to complement it). M oreover, even if expected outcomes are the same (because, for instance, two individuals choose the same conjectures as complement to their informational set) the resulting action

\footnotetext{
${ }^{3}$ This author has tried to do it in Cardim de Carvalho (1988). In that paper, the detailed references upon the interpretation being presented here relies are provided.

${ }^{4}$ Keynes's concept of uncertainty applies to situations where the universe of outcomes resulting from a given cause cannot even be fully described ex ante, so that the full certainty that one of those events will in fact take place cannot be distributed among the possible outcomes. Decision makers know that there are risks in the future that they cannot identify (or protect against) at the moment of decision. They have to create a picture of what the future may be. In contrast, with calculable probabilities one is dealing with a known universe of possibilities and knows that one of those events will materialize in the future and nothing out of that set of events can take place. Expectations formation as an act of creation was a lifelong interest of Keynes's follower G.L.S. Shackle. See, for instance, Shackle (1979).

${ }^{5}$ Thus, Keynes should not be taken as a precursor of behavioral finance or behavioral economics. The latter searches for instances of irrational albeit systematic behavior while Keynes sought to explain how individuals make rational choices when they know they are exposing themselves to risks generated by the incompleteness of information at the moment of decision. See, for instance, Kahnemann (2013).
} 
may not be the same if the degrees of confidence on the expectations held by each individual are different. In other words, there is no way, in Keynes's view, to establish a direct connection between direct knowledge (that is, observable data) and decisions.

Keynes's skepticism with respect to the possibility of irrational behavior being relevant was maintained throughout his life. In 1930, for instance, discussing how expectations would react to recovery programs during the crisis, Keynes was blunt:

As regards psychology, I maintain that if I am right that a large capital programme would increase the profits of business men, this would, after the first blush, have more effect on them than anything else." (Keynes, 1981, p. 361). ${ }^{6}$

In fact, during all this period, there were many occasions where Keynes had the opportunity to defend the idea that experience was the strongest determinant of expectations. A few years later, in The General Theory, Keynes was still warning against the reliance on the argument of irrationality to explain the instability of the economy (Keynes, 2007, pp. 162-3).

Keynes's approach to expectations and uncertainty, thus, attempted to transcend at the same time a mechanistic bias whereby agents responded in automatic ways to specified stimuli and the assumption of irrationality. Keynes's point is that individuals do make non-empty choices because they are choosing among outcomes of their own creation but once the outcomes are identified the choice among them is rational, that is, is derived from a calculation of costs and benefits, given the confidence agents place on their own beliefs.

In The General Theory, Keynes maintained the same essential views presented in the Treatise on Probability but took a step forward to reconcile the two apparently incompatible notions he had maintained until then. The Treatise view emphasized the element of creativeness in expectations formation, since the formulation of conjectures is a condition for the derivation of implications of a given informational set among which the decision maker will make his or her choices. The appeal to conjectures implies that there is always some degree of autonomy in the formation of expectations with respect to objectively experienced reality. But, as we saw above, Keynes also believed that current incentives (such as earning profits from capital investment programs) would have something like a direct impact on expectations.

\footnotetext{
${ }^{6}$ In a statement to the MacM illan Committee, Keynes elaborated the point, delimiting in the process his view of the role of fiscal policy in promoting recovery from a recession: "In conclusion I should like to say about Government action of this kind, that obviously it cannot be a permanency. You cannot be permanently stimulating local authorities to anticipate their programme, and you cannot permanently be going ahead at a great pace with public developments. Nevertheless I think the first impetus forward must come from action of this kind, that it must be Government investment which will break the vicious circle. If you can do that for a couple of years, it will have the effect, if my diagnosis is right, of restoring business profits more nearly to normal, and if that can be achieved then private enterprise will be revived." (Keynes, 1091, pp. 146-7). Later, in July 1931, Keynes seemed to be more cautious, at least with respect to the financial system, badly burned by the Stock Exchange crash and the episodes of bank runs: "There is a certain point where almost everybody in charge of funds reaches the stage of what I call 'abnormal psychology'. In an ordinary way, any kind of financial institution has a certain cushion of some kind, reserves and margins, and is prepared to run reasonable risks, prepared to be sensible on the evidence, but when those margins run down to a certain point they get into a state of mind where they are not prepared to run even an actuarial risk or better than an actuarial risk. They just won't run any risk at all, because they have got to the end of their margins. If they would run any risk at all, and it was to go wrong, they would be in a horrid situation, and as credit and security is their total stock in trade, they get into a state of mind where they won't run a sound risk." (Keynes, 1981, pp. 536-7). One should notice, however, that abnormal psychology is not a reference to irrational fears, but to extreme exposure to reasonable risks, to be considered in any rational decision process.
} 
Keynes reconciled the two views by differentiating between short and long term expectations (Keynes, 2007, chapter 5). Short term expectations oriented choices which affected the immediate future, like, typically, production decisions. Long term expectations oriented behavior directed at targets located farther in the future. The first group of expectations would be practically determined by the "most recent results". ${ }^{7}$ Long term expectations were another matter. Hard information about the far future is scarcer so the weight of conjectures in the decision process is increased. This means that "[t]he state of long-term expectation ... does not solely depend ... on the most probable forecast we can make. It also depends on the confidence with which we make this forecast - on how highly we rate the likelihood of our best forecast turning out quite wrong." (Keynes, 2007, p. 148, Keynes's emphasis)

Thus, repetitive operations, which can be assumed to happen within a reasonably stable environment, are oriented by short term expectations. Learning is possible because the process preserves its basic characteristics long enough for them to be identified. Under conditions such as these, expectations are basically adaptive. In equilibrium, Keynes assumed them to accurately reflect actual conditions. ${ }^{8}$ However, with long term expectations it is another matter entirely. Forecasts cannot be trusted to accurately depict far-in-the-future situations. Innovations are possible so that learning is limited by the continuous obsolescence of past information. The weight of the state of confidence means that subjective factors are irreducible to objectively observed current conditions. Long term expectations should be treated, therefore, as theoretically exogenous. They may be, and certainly are, influenced, perhaps heavily, by current conditions but are not determined by these conditions.

Formally, therefore, short term expectations are endogenous, but long term expectations are exogenous to the theory of employment proposed in The General Theory. But besides proposing this dichotomy, there is another, perhaps more important, implication derived from Keynes's theory of expectations.

As already mentioned, Keynes entered the discussion of induction in the Treatise motivated not by the epistemological dimensions of the debate but by its behavioral implications. How rational can the reliance on inductive reasoning be to orient making decisions, that was the question that interested Keynes. The main point was that induction is never enough to generate certainties but it can be powerful enough to determine some degree of confidence on what one believes to be true. The central point is that Keynes explicitly assumes that the individual not only has to decide with insufficient hard information but also that he knows that the information on which the decision relies is insufficient to allow drawing certain conclusions. The implication of this assumption is that the decision maker is aware that he is accepting exposures to risks that cannot even be named (let alone insured against) at the moment of decision. This is an essential characteristic of economic behavior as postulated by Keynes. Awareness that information is hopelessly insufficient (because the future can never be known before it happens, when it will be too late for the information to have any value) imparts to all decision making, according to Keynes, a precautionary concern that modifies, sometimes substantially, the way the economy works.

Two results follow from this: 1 . Keynesian economic agents are permanently in the look out for new information that can signal that things developed in a different way from what was expected and

\footnotetext{
${ }^{7}$ As Keynes (2007, p. 51) argued: "It would be too complicated to work out the expectations de novo whenever a productive process was being started; and it would, moreover, be a waste of time since a large part of the circumstances usually continue substantially unchanged from one day to the next."

${ }^{8}$ That is why there is no discussion of possible divergences between expected demand and actual demand in the theory of employment presented in The General Theory or any consideration of the occurrence of unwanted inventories: production decisions are supposed be based on accurate expectations of demand so that no mistakes are made or are needed to be corrected in the model.
} 
that therefore new decisions should be made to adapt to newly discovered circumstances; 2 . Every decision to be made should take into consideration not only its explicit goals but also how much flexibility it gives the decision maker to alter his strategy in the case where changes of route become eventually required.

In other words, Keynes's theory of expectations implies that economies are potentially unstable, since new information can lead to drastic re-assessments of desired strategies by economy agents ${ }^{9}$ and that defensive forms of behavior are pervasive and can be identified in every major group of decisions individuals have to make.

\section{Decision Making under Uncertainty and Keynes's Theory of Employment}

It can be easily shown that all theoretical innovations presented in The General Theory relate to the assumption of pervasiveness of defensive behaviors in modern market economies. Keynes's point was that acknowledging the importance of expectations formation under non-measurable uncertainty meant that one should aim at explaining how economic behavior, even rational economic behavior, is changed in comparison to situations of certainty or measurable risk. The tradition that prevailed in conventional models was rooted in von Neumann and Morgenstern (1944). For these authors, measurable risk modified the value of goods at the eyes of economic agents, but did not change their choice behavior. As von Neumann and Morgenstern (1944, pp. 27-8) argued, if one can define preferences for v over $u$, one can also define preferences for a chance of v over a chance of $u$. Therefore, taking risk into consideration it was just a matter for properly ranking chances of events in the preference scale, as long as the chances of $u$ and $v$ can be measured. ${ }^{10}$

Keynes took an entirely different path. His main proposition is that agents act in different ways in the face of uncertainty, that is, their pattern of behavior is changed and, thus, the dynamics of an entrepreneurial economy which is based on the assumption that uncertainty cannot, in certain cases, be measured, is likewise changed. The General Theory was written to explain how it would work. In a closed economy with no government, aggregate demand comprises consumption and investment. To analyze them, Keynes introduced three concepts: the propensity to consume, the marginal efficiency of capital and liquidity preference.

The propensity to consume is the function that connects the decision to buy consumption goods to its determinants. There are many variables that may help to determine aggregate consumption, but Keynes singles out income. In his theory, consumers decide how much to consume and how much to save mainly as a function of their income level. Why? Keynes argues that the consumption/saving choice is a complex decision where many (objective and subjective) variables are involved. Among these variables, Keynes mentions, at the top of the list, for households "to build up a reserve against unforeseen contingencies" (Keynes, 2007, p. 107), that he calls the Precaution motive (idem: 108). For business firms, four reasons to save are given, two of which (liquidity and financial prudence) have to do with the same precautionary concern (idem, pp. 108-9). At least in the case of households Keynes seemed to suggest that one of the main reasons to save was to make sure that a given standard of living

\footnotetext{
${ }^{9}$ Some authors follow Keynes's lead in this point to postulate that institutions evolve in modern economies precisely to help controlling this inherent instability, either by socializing its negative consequences or to channel its deleterious effects to less important areas of the economy. Keynes inaugurated this line of reasoning in The General Theory when discussing the role of the Stock Exchange (Keynes, 2007, chapter 12). Paul Davidson (1978) extends another of Keynes's insights to the role of money forward contracts.

${ }^{10}$ Debreu (1959) is an alternative way to obtain a similar result. Instead of comparing chances of a given result, Debreu postulates the existence of complete markets, so that for every "chance" of getting a given good its value can be properly computed.
} 
could survive economic adversities. The higher the level of income that is attained, the higher savings have to be to ensure that. ${ }^{11}$

With respect to the marginal efficiency of capital, i.e. the rate of return on investments, Keynes emphasized the importance of institutions like Stock Exchanges to give an investor a way out of a given initiative on the attractiveness of investment opportunities. Illiquidity is a big minus in the decision to buy capital goods (Keynes, 2007, pp. 150-1).

Finally, liquidity preference is in itself a model of defensive behavior. The best evidence that this is what Keynes had in mind is his reply to critics of The General Theory, led by Jacob Viner, in 1937. In this paper, titled "The General Theory of Employment", Keynes defended his concept of uncertainty, as described above, and argued that:

[...] partly on reasonable and partly on instinctive grounds, our desire to hold money as a store of wealth is a barometer of the degree of our distrust of our own calculations and conventions concerning the future." (Keynes, 1973b, p. 116)

Liquidity preference relates to the desire of individuals to keep assets in liquid form, and money is the most liquid of all assets. The return money offers as an asset is its liquidity premium, its power of disposal (Keynes, 2007: 226). Individuals demand money when uncertainty rises, penalizing less liquid assets that do not offer their holders the same degree of flexibility guaranteed by liquid assets. But "because the facilities for hoarding are strictly limited ... liquidity preference mainly operates by increasing the rate of interest. ... A rise in the rate of interest is a means alternative to an increase of hoards for satisfying an increased liquidity preference." (Keynes, 1973b, pp. 110-1, Keynes's emphasis)

Therefore,

The possession of actual money lulls our disquietude; and the premium which we require to make us part with money [that is, the rate of interest] is the measure of the degree of our disquietude. (idem, p. 116)

To summarize Keynes's theory of employment advanced in The General Theory, it is proposed that in a closed economy without government aggregate private demand may be insufficient to support full employment when individuals and firms decide to save and to retain non-consumed income in the form of liquid assets. The jobs that are lost in the production of consumption and investment goods that are not desired by private agents are not recovered in the production of liquid assets, particularly money. Keynes called the resulting unemployment involuntary because, in his view, there was nothing workers could do to increase employment since entrepreneurs know that an increased output will not be saleable anyway.

\section{Minsky and Keynes}

Keynes wrote his works mostly during hard times and it seemed only natural to assume that high uncertainty was a strong factor causing individuals to retreat from consuming and investing. Uncertainty fed the fears of the population as to what to expect of the future and led consumers and firms to build stocks of liquid assets instead of taking the risks involved in spending. As private agents retreated to safe forms of wealth accumulation the economies deteriorated and unemployment rose, confirming the worst expectations of the public and feeding a new round of precautionary demands.

Minsky, in contrast, was an American Keynesian economist writing in a different time and under completely different circumstances. The ghost of the depression was still present in the minds of

\footnotetext{
${ }^{11}$ A few authors developed a theory of precautionary or "buffer" savings, without apparently taking notice that Keynes had already advanced such possibility. See, for instance, Deaton (1999) and Carroll and Summers (1991).
} 
macroeconomists in the immediate post-war years in the United States but the country was in fact living the beginning of a golden age of economic growth and prosperity that was to last until the mid-1960's. In such an environment, a theory of expectations and behavior that highlighted the influence of uncertainty and confidence was to become surprisingly liberating. M insky accepted that uncertainty is the root of instability. ${ }^{12}$ However, his immediate concerns are the exact opposite of Keynes's:

It turns out that the fundamental instability of a capitalist economy is a tendency to explode to enter into a boom or 'euphoric' state. (Minsky, 1982, p. 118)

In a prostrated environment such as the one in which Keynes wrote The General Theory, when Great Britain lived through a durable recession (initiated with the return to the gold standard at an overvalued exchange rate in 1925), and the United States and a large number of other countries suffered the Great Depression of the 1930's, raising the argument of confidence served to stress why individuals and firms shied away from the spending on goods and services that was necessary to support employment. On the contrary, in the euphoric environment of the post war American economy in which Minsky wrote his works, acknowledging the role of confidence served to stress how overconfident investors and financial institutions could take the economy to unsustainable levels of activity. Keynes argued that lack of confidence led to unemployment. Using the same theory, M insky argued that excess confidence could lead to overheating and inflation.

In M insky's approach, the most important decision an agent has to make in a capitalist economy is how to build his or her balance sheet (M insky, 1975, pp. 86-7). Assets are purchased primarily to earn money returns, liabilities are issued to finance these purchases. Cash inflows expected to be generated by the ownership of assets have to be sufficient to allow the individual to honor the cash outflow commitments represented by liabilities. Agents are exposed to insolvency risk because even if cash inflow expectations are disappointed, cash outflow commitments have still to be honored. They are also exposed to illiquidity risk because cash inflow expectations may be enough to cover cash outflow commitments but not in the right time, which is the settlement date defined in contractual liabilities. To manage the two risks, every agent, no matter if they are households, firms or banks, tries to build a margin of safety between assets and liabilities. These safety margins may be defined in terms of liquidity buffers, i.e. assets that are held not for their monetary returns but for their liquidity, or in terms of excess expected returns over committed payments making it possible to settle debts even when expectations of cash inflows are partly disappointed. The safety of the balance sheet is, thus, directly dependent on the appropriate margins of safety being set. Under uncertainty, however, these calculations are directly affected by changes in the state of confidence. In euphoric times, the particular case that interested Minsky, these margins may be set at levels that are too low to effectively protect the balance sheet because investors and financial institutions believe that risks are in reality low. ${ }^{13}$ Minsky called these states financially fragile in the sense that even a small shock may be enough to

\footnotetext{
12 "To understand Keynes it is necessary to understand his sophisticated view about uncertainty, and the importance of uncertainty in his view of the economic process. Keynes without uncertainty is something like Hamlet without the Prince." (Minsky, 1975, p. 57) A few pages later, M insky added: "Uncertainty enters strongly into the determination of behavior at two points: in the portfolio decisions of households, firms and financial institutions, and in views held by firms, by the owners of capital assets, and by the bankers to firms as to the prospective yields of capital assets." (Minsky, 1975, p. 67)

${ }^{13}$ As Keynes before him, Minsky did not postulate that agents irrationally underestimated (or overestimated) risks. In fact, Minsky relies strictly on the assumption of rationality stating that estimates of risks follow actual experience, in a similar way to Bayesian evaluations of probabilities. When an economy remains prosperous for some time, risks estimated statistically tend to fall. At the same time, confidence tends to be strengthened when a bet on prosperity is continuously confirmed by actual developments. This is what Minsky meant with his wellknown aphorism stability is destabilizing.
} 
cause households, firms and financial institutions to find themselves illiquid and, in the worst case, insolvent. If financial fragility is widespread such adverse shock may generate a financial crisis, as it happened in 2007/8 in the United States. If a crisis does take place, then Keynes's predictions come back in force. Uncertainty now justifies excess fears, rising liquidity preferences and paralysis. If left unchecked, the financial crisis may become an economic crisis, again as it did in 2008/9 in the United States and Western Europe.

\section{Conclusion}

The notion that Milton Friedman and Robert Lucas introduced the issue of expectations against Keynesians is reasonable if one is talking strictly about what was known as hydraulic Keynesianism but is preposterous as a criticism of Keynes's own approach. In fact, expectations were a central theme in his reflections even before he decided to focus on economic problems. Moreover, Keynes's approach to expectations was much richer than the desiccated treatment the theme received by proponents of adaptive and rational expectations hypothesis alike. While in New Classical theories, for example, the rational expectations hypothesis is proposed just as a means to get rid of the problem of how expectations are actually formed, ${ }^{14}$ Keynes wanted to actually incorporate in his theories the implications of taking fundamental uncertainty at face value.

The result was an approach that stressed two of the implications identified in the exercise. First, expectations formed on the basis of a combination of direct knowledge and conjectures are fragile and therefore the processes oriented by them are unstable. Second, assuming that agents are fully aware of the extent to which they rely on conjectures implied that flexibility to change their positions as new information was received was valuable to wealth holders, which explained liquidity preference but also other decisions of a at least partial precautionary nature. Uncertainty, as seen by Keynes, imparted a deflationary bias on the operation of the economy because it reduced agents' disposition to spend in favor of the accumulation of illiquid assets.

But acknowledging the role of confidence, and of variations in the state of confidence, allowed Minsky to turn Keynes's ideas around and to propose that under different circumstances, changes in confidence could explain euphoric states, an inflationary rather than a deflationary bias. Minsky used basically the same concepts of uncertainty and expectation formation to derive a theory of financial fragility instead of involuntary unemployment.

\section{References}

Cardim de Carvalho, F. J. (1988) "Keynes on probability, uncertainty and decision making", Journal of Post Keynesian Economics, 11 (1), Fall, 66/81.

Carroll, C. and Summers, L. (1991) "Consumption growth parallels income growth: some new evidence", in B.D. Bernheim and J. Shoven (eds), National Saving and Economic Performance, Chicago: The University of Chicago Press.

Davidson, P. (1978) M oney and the Real World, London: MacM illan, 1978.

Deaton, A. (1999) "Saving and Growth", in K. Schmidit-Hebbel and L. Servén (eds), The Economics of Saving and Growth, Cambridge: Cambridge University Press.

\footnotetext{
${ }^{14}$ Sargent (1994) seems to give some support to this interpretation.
} 
Debreu, G. (1950) A Theory of Value, New Haven: Yale University Press.

Heller, W. (1966) New dimensions of political economy, Harvard University Press.

Kahnemann, D. (2013) Thinking, Fast and Slow, New York: Farrar, Strauss and Giroux.

Keynes, J. M. (1973a) A Treatise on Probability. The Collected Writings of John Maynard Keynes, vol. VIII, London: MacMillan for the Royal Economic Society.

Keynes, J. M. (1973b) The General Theory and After. Part II: Defence and Development. The Collected Writings of John Maynard Keynes, vol. XIV, London: M acM illan for the Royal Economic Society.

Keynes, J. M. (1981) Activities 1929-1931. Rethinking Employment and Unemployment Policies. The Collected Writings of John Maynard Keynes, vol. XX, London: MacMillan and Cambridge: Cambridge University Press for the Royal Economic Society.

Keynes, J. M. (2007) The General Theory of Employment, Interest and Money, London: Palgrave MacMillan.

Minsky, H. P. (1975) John Maynard Keynes, New York: Columbia University Press.

Minsky, H. P. (1982) Can 'It' Happen Again? Essays on Instability and Finance, Armonk: M .E. Sharpe.

Sargent, T. (1944) Bounded Rationality in Macroeconomics, Oxford: Oxford University Press.

Shackle, G. L. S. (1979) Imagination and the Nature of Choice, Edinburgh: Edinburgh University Press.

Von Neumann, J. and Morgenstern, O. (1944) Theory of Games and Economic Behavior, Princeton: Princeton University Press. 